\title{
Instructing new Online Educators with Effective e- Learning Management Systems (eLMS) Skills and Techniques
}

\author{
Bob Barrett \\ American Public University, Charles Town, West Virginia, USA
}

\begin{abstract}
Creating the good teaching experience for new online educators is important, but many new teachers are limited with technological skills or little (if any) e-learning management systems background. The transition from Face-to-Face (F2F) traditional live classroom to a new virtual one involving online learning skills and knowledge to be used on a e learning management system may be daunting and even terrifying for some new virtual instructors. However, a good online instructor should be able to create the appropriate learning environment to walk new teachers from the onset of what is an e-learning management systems to creating their own practice classroom (or sandbox) to help practice necessary skills and techniques needed by today virtual (online instructors). For the purposes of this paper, the Blackboard and other e-learning management systems platforms will be examined.
\end{abstract}

Keywords-component; e-learning management systems; virtual learning; adult education; online education, teaching techniques.

\section{INTRODUCTION TO VIRTUAL LEARNING}

Education is changing, and what we know as the traditional classroom will soon be a thing of the past. We have seen the metamorphosis of the traditional classroom setting transform into a virtual (online) one quickly over the past two decades. What we used to know as distance education is now referred to as online or virtual learning. However, there has been resistance by many in the academic field as to its use and legitimacy. According to a study by the Babson Survey Research Group (2013), it reported in their publication, 2013 Survey of Online Learning, that the number of U.S. higher education learners enrolled in at least one online course has now exceeded 7.1 million. [1] While many academic and public critics have argued that most academic institutions may continue to hold steadfast to traditional teaching methods, this new and growing form of learning is now catching more momentum and has gained more social acceptance and profits than previously anticipated. Further, Allen (2013) noted that, "While the rate of growth in online enrollments has moderated over the past several years, it still greatly exceeds the growth in overall higher education enrolments." Further, this survey’s findings indicated that " $33 \%$ of higher education students now take at least one course online, while $90 \%$ of academic leaders believe that it is likely or very likely that a majority of all higher education students will be taking at least one online course in five years' time." [2][3] What we need to consider is that today's adult learner wants a different way of obtaining education than previously offered. Many of these returning adult learners probably would not be returning back to the classroom - if education and its previous "un-enticing” appeal was linked to it. Rather today, online learning is offer a refreshing alternative that adult learners, instructors, and administrators are making the switch over to this new form of technological empowerment and education.

\section{School Closings, Smaller Classes, AND NeEd FOR SURVIVAL}

Now that we have established that traditional face-to-face (F2F) physical learning environments have been losing ground in terms of the needs for today's returning adult learners, we need to consider the reasons why adults need additional education and/or training. The economy and harsh economic times have been a problem for many workers and their family members. What was once a required and mandated learning environment has now been changing with the impact of the economy and decision making by governmental officials and academic administrators.

Let us consider some examples of why there are some school facing the decision of carrying on traditional education and struggling tuition rates versus those schools going online with their educational offerings. According to a recent article by Rocco (2015), "Lawmakers in South Carolina are pushing for a temporary shutdown of South Carolina State University, hoping to give the 119-year-old school a clean slate. In Ohio, where schools face the possibility of reduced funding, Gov. John Kasich is asking schools to make cuts. Other states such as Wisconsin also are looking for universities to slim down.” [4] These state schools are facing real and perhaps ultimate decision making by lawmakers and school officials when the books do not reflect enough numbers to meet budgetary needs. Further, Jaschick (2015) wrote on the final decision of closing of Sweet Briar College in the U.S. He wrote that "Sweet Briar was founded in 1901, and has operated as a women's liberal arts college throughout its history, known for small class sizes and close student-faculty interaction. The college is considered a pioneer in study abroad and operates a leading study abroad program in France. Sweet Briar's equestrian program is also nationally acclaimed. [5] Historically, this liberal arts college has taken pride in its reputation for small class sizes and attracting female students to its "institutional way of instruction and thinking." In light of these economic considerations, let us consider what are the current needed characteristics for instructors to work in this new learning environment. 


\section{EXAMINATION OF INSTRUCTOR CHARACTERISTICS AND SKILLS SETS}

We need to consider that some instructors are more effective in one or more different types of learning environments. Their talents may be noticeable and yet, some have yet to explore their "technological wizardry". This has been true in both the traditional and online class environments. We have seen the teaching environment change from the days of just teaching classes with the traditional blackboards to more modernization. Today, we have electronic blackboards and students are usually more interested in logging into a classroom on their own time - rather than a prescribed date and time of class meetings. Harris (2000) commented that the "new workplace requires a new type of employee, one who is highly skilled, flexible, creative, and attuned to working as a member of a team.” [6] With this new workplace in mind, academic institutions need to prepare their current and new instructors for this type of new employee. Thus, they need to utilize different types of recruiting and hiring methods to find the best-qualified instructors. Further, these educational institutions need to focus on training online instructors to be able to work with the training entity, whether it be an institution of higher education or training learning center, in order to develop and design, implement, and evaluate current and future educational offerings. As a result, both education for the workplace has changed drastically, and academic institutions will have to make concessions and implement changes in order to compete in today's marketplace.

One important fact is that some educators may not desire to teach any more in the normal regular Face-to-Face (F2F) classroom, and they may be seeing a change of venue. Thus, we have to ask as to what are the characteristics of a good and bad online instructor? Roueche, Roueche, and Milliron (1995) stated, "Adjunct faculty are increasingly important players in the teaching and learning process. It is in the college's best interest of appreciating the investment value of them, and ultimately in the interest of establishing and maintaining the college's reputation for teaching excellence.” [7] Therefore, many schools have found that this helps to reduce some administration of benefits and pay - so part-time faculty have been a "quick fix" for their current need. Nonetheless, it should be noted for the purposes of this paper that there may be a change in this situation within recruiting and hiring over the next decade, but for the past three decades, part-time hiring has been the trend. [21]

It should be noted that many online teaching positions are being filled by part-time instructors due to economic reasons and their availability. However, we should also note that may school do not and cannot afford to pay out large sums for benefits, so the use of adjunct (part-time) faculty is more economically feasible. Consequently, we can expect that more part-time faculty may anticipate and seek more pay and benefits (i.e., unions, professional organizations, etc.). Therefore, what does this mean? This means additional training will be needed, and there will be a great need to diagnose and examine training methodologies in terms of teaching strategies and techniques.
It is should be noted here that training is not as easy as some candidates might think at first. If the instructor has never worked on a computer or taken an online learning course, he or she might need some additional work. Whereas, many online instructors have been able to transition over successfully to the online teaching environment. Online training sessions can span from 3 hours to 6 weeks, depending on the Learning Management System (LMS) and learning the various rules, procedures, and regulations of the university system. It is during this time when the training and/or department chair can determine early on whether or not a new hire for online teaching will succeed or not. As a result, it should be noted that during the training period, many faculty members have been issued a potential class to work in, along with the teaching materials. [8] Therefore, we need to examine the current technological requirements and skills needed for today's online educators.

\section{OVERVIEW OF NECESSARY ONLINE TECHNOLOGICAL REQUIREMENTS AND SKILLS}

While teaching may not be for everyone, one can learn some necessary skills sets to help them with teaching and to experience whether or not the online or live learning environments are the best way for them to become an effective teacher. Thus, while some people may not enjoy driving to a physical classroom to lecture for class periods of 2-3 hours straight, some have seen the opportunity to teach in their own home or office on an arranged scheduled as not only a benefit but a necessity in terms of other factors affecting their lives. Therefore, any new virtual instructor needs to assess his or her skills sets in order to determine if he or she possesses the necessary skills to become an online instructor. Here is a quick overview of the key minimum requirements needed for online teaching.

- Technological Skills

- Is the candidate computer literate?

- Can the candidate use email, word processing, and spreadsheet software?

- Educational Skills

- Does the instructor have a master's degree with at least 18 graduate credits in the given subject area?

- Teaching Skills

- Has the candidate taught before (private or public sectors)?

- Work Experience

- Does the candidate have work/industry experience?

The above list represents only a sample of item to asses a potential online instructor. It should be noted that as more elearning management systems platforms are developed, this list may need some modifications or additions made to it. Now, let us explore yet another segment of online learning that affects not only the students, but also the teachers. We need to remember that there will always be a need to change and adapt to various types of instructions methods. 


\section{IDENTIFyING InStRUCTIONAL Methods AND UsES}

Since the days of Socrates, course instruction (lecture method) d has been given in a physical, live classroom. However, the environment has changed with the introduction of online learning. Here are some examples of components, or activities, offered in Traditional Teaching and Online Teaching.

Traditional Face-to-Face (F2F) Teaching Methods

- Classroom Lecture - Live

- Demonstrations - Live

- Assignments - Live (or in Syllabus)

- Classroom Discussions - Real Time

- Exams - Timed or Distributed

Online Teaching Methods

- Classroom Lecture - Recorded or Live

- Demonstrations - Recorded or Live

- Assignments - Posted for Students

- Classroom Discussions - Discussion Threads or Real Time Discussions

- Exams - Timed or Distributed

It should be noted that a good instructor training program will examine both the F2F and online learning environments, just in case if the new educator might not be sure if online teaching is the best route for him or her at that time. In any event, the following section will highlight sample online instructional strategies, which can be used for new and current instructors.

\section{ENGAGING AND EFFECTIVE INSTRUCTIONAL STRATEGIES WITH E-LEARNING MANAGEMENT SYSTEMS} (ELMS)

Let us take a quick overview of strategies. In addition, this section will give examples of how these strategies can be used in one specific e-Learning Management System platform called Blackboard. What makes a creative and innovative instructional strategy? What is the importance of the variety of strategies? One of the key problems that online consultants and evaluators discover when reviewing any type of learning environment may be focused on the effectiveness of not only the instructor, but also the instructional methodologies used (or perhaps not sued). Zhu, Payette, DeZure (2006) [9] wrote about several areas of consideration when one is creating an online course: 1) course content; 2) delivery of instruction; 3) communication and interaction; 4) student time spent on learning tasks; and 5) assessment of student learning. Whereas, the course content may remain the same, the delivery of instruction will be given either synchronous or asynchronous learning formats. Instead of live discussion in a physical classroom, the discussion/dialogue will be done in a chat session, discussion thread, and/or video session. Thus, the learner's participation in the course will depend on the learning format, as designed. Therefore, assessment of student learning can be done in terms of live chats, discussion threads, assignments, quizzes/exams, and/or projects. Finally, in order to consider such items within a course design, one needs to look at key areas to incorporate each of these items.
Another model that could be helpful in examining a learning environment is described by Salmon (2000). [10] This author's five-step model focuses on the interaction between students and students and their instructors in terms of the quality and intensity of their interactions.

Step 1 - Access \& Motivation

Step 2 - Online Socialisation

Step 3 - Information Exchange

Step 4 - Knowledge Construction

Step 5 - Development

The next step is to offer some examples and application points of this model to enable the reader to see the relevance of such a model in a learning environment.

Step 1 - Access \& Motivation. The key to good interaction within a research class is discussion and contact.

Strategy: What is research? An instructor could develop a PowerPoint Presentation (PPT) to help overview the concept of research. Not all students will read the first chapter of any textbook or required readings, but rather they will skim the material until they realize "what they need to know." Also, in a class setting, there could be students with learning disabilities (i.e., dyslexia, dysgraphia, dyscalculia, dyspraxia, non-verbal learning disorder, etc.) (DO-IT, 2010)[11]

In the Blackboard system, the instructor can develop PowerPoint slides, or use publisher's slides, to help reinforce the learning material for the students. Also, the use of announcements on the first webpage of the eLMS platform is important to keep the students up to date with events, deadlines, and to help guide them through the course. The use of Voki or other Web 2.0 or 3.0 tools can be useful in this section.

Step 2 - Online Socialisation. Students will be slow at times to interact, unless they are required or if something "captures their interests." While many people have argued about the loss of socialization in the online learning environment, many instructors have focused on this particular area. Irwin and Berg (2006) stated that "Socialization is about people being able to mingle and establish connections on one or more levels. They speak [with] one another; share ideas and information and confirm the connections made through an agreed upon means.” (para. 3)[12].

Strategy: What is research? The first main discussion should be based on what is research. It is important to determine a baseline of what the students know now, perhaps in a form of a type of pre-assessment.

In the Blackboard system, the Discussions section is a vital tool for all educators and learners. The instructor can pose all types of educational, content knowledge, ethical, or general questions in this area with the intent of building a learning community and developing weekly dialogues.

Step 3 - Information Exchange. During this step, the students need to know how to look at problem situation and determine the factors affecting the person(s), situation(s), event(s) and/or location(s). It is during this time that the instructor can play a major role to involve all students - and focus on their learning styles. 
Strategy: How is research collected? In order to meet the learning of various learners in the course, it is recommended that the instructor offer PowerPoint Presentations, audio lectures, as well as text-based documents.

In the Blackboard system, as previous noted, has a variety of tools. One can set up assignments and collect written research, offer surveys within the course, and/or offer quizzes and other assessment instruments to measure the learner's mastery of the course content knowledge.

Step 4 - Knowledge Construction. How research is used and how it is approached is important. While some students may be more auditory than others, there will also be visual, kinesthetic, and environmental learners (further discussion will be held later on this topic).

Strategy: How is research analyzed? As discussed in the previous strategies, the methodology taught by the instructor and used by the student is important. Depending on the student's learning style, the use of various learning activities and methods of teaching will either help enhance or detract from the learning experience.

In the Blackboard system, groups can be arranged in which projects can be worked in various part of the eLMS platform, as well as groups in the Discussions sections. In particular, this system allows the instructor to set up various assessment areas and rubrics to help grade and given feedback to learners.

Step 5 - Development. The final part of any course is the development of the final project and connection to all components of the course at this stage. As noted in the above strategies, it is the intent of the course to cover all course objectives, provide learning activities, as well as offering a final assignment, project or exam in which the instructor can assess the final level of learning for students.

Strategy: How is research written up? This is one area that many instructors will argue or agree upon - the format for writing up research.

In the Blackboard system, as noted in previous sections, there are multiple course tools to use for project, discussions, assessment, and collaboration learning activities for the adult learners. However, it should be noted that not just one training session can be feasible for all educators to master such tools. Advance training sessions could be beneficial for all online educators learning this eLMS platform as a form of ongoing or professional development.

\section{CONCLUSION}

As more technology is developed and academic standards and accreditation requirements continue to change, the field of online learning will continue to develop and grow. It should be noted that online courses and programs will need to be monitored, analyzed, and evaluated for improvement in terms of efficiency and effectiveness in meeting the learning needs of the adult learner of today. Nonetheless, there will always be a growing need for more research and evaluation of online learning in terms of the teaching personnel and their instructional methodologies. Consequently, we, as educators, should always be attuned to these changes and the need for continuous learning ourselves to help keep our teaching and academic currency updated regularly.

\section{REFERENCES}

[1] Babson Survey Research Group (2013). 2013 US Survey of Online Learning Published. Retrieved http://www.icde.org/2013+US +Survey+of+Online+Learning+published.b7C_wRjQXf.ips.

[2] Allen, as noted in Babson Survey Research Group. 2013 US Survey of Online Learning Published. Retrieved http://www.icde.org/2013+US +Survey+of+Online+Learning +published.b7C_wRjQXf.ips, (2013)

[3] Babson Survey Research Group (2013). 2013 US Survey of Online Learning Published. Retrieved http://www.icde.org/2013+US +Survey+of+Online+Learning+published.b7C_wRjQXf.ips.

[4] M. Rocco (Feb. 16, 2015). Closing the door on public colleges? FOXBusiness. Retrieved Nov. 1, 2015 from http://www.foxbusiness .com/economy-policy/2015/02/13/closing-dooron-public-colleges/.

[5] S. Jaschick (Mar. 4, 2015). Shocking decision at Sweet Briar. Inside HigherEd. $\quad$ Retrieved Sept. 30, 2015 from https://www.insidehighered .com/news/2015/03/04/sweet-briar-collegewill-shut-down.

[6] H. Harris (2000). Defining the future or reliving the past? Unions, employers, and the challenge of workplace learning. Columbus, $\mathrm{OH}$ ERIC Clearinghouse on Adult, Career, and Vocational Education, Information Series, No. 380.

[7] J.E. Roueche, S.D. Roueche, and M.D. Milliron (1995). Strangers in their own land: Parts-time faculty in American's community colleges. Washington D.C.: Community College Press.

[8] K.M. DeWalt, \& B.R. DeWalt, (2002). Participant observation: a guide for fieldworkers. Walnut Creek, CA: AltaMira Press.

[9] E. Zhu, P. Payette \& D. DeZure (2006). An introduction to teaching online. CRLT Occasional Papers. Center for Research on Learning and Teaching, University of Michigan. No. 18.

[10] G. Salmon (2002). E-tivities. The key to active online learning. London: Kogan Page.

[11] DO-IT Home (2010). Learning disabilities. Retrieved April 15, 2010. http://www.washington.edu/doit/Stem/ld.html.

[12] C. Irwin, \& Z. Berg, (2006). Socialization in the online classroom, Irwin, C., and Berge, Z., e-Journal of Instructional Science and Technology, Vol. 9 No. 1, March, 2006, Retrieved April 10, 2010. http://www.usq.edu.au/electpub/ejist/docs/vol9_no1/papers/full_papers/irwin_berge.htm. 